\title{
Study of Samuelson's General Model of National Economy and Definition of Asymptotic-Stability Conditions
}

\author{
Athanasios D. Karageorgos ${ }^{1}$ \& Grigoris I Kalogeropoulos ${ }^{2}$ \\ ${ }^{1}$ Department of Computer Science, University of Thessaly, Greece \\ ${ }^{2}$ Department of Mathematics, University of Athens, Greece \\ Correspondence: Athanasios D. Karageorgos, Department of Computer Science, University of Thessaly, Greece
}

Received: July 30, 2018 Accepted: August 27, 2018 Online Published: September 6, 2018

doi:10.5539/jmr.v10n5p129 URL: https://doi.org/10.5539/jmr.v10n5p129

\begin{abstract}
In this particular paper we firstly deal with Samuelson's model of national economy. We create a difference equation which reflects Samuelson's model for the national income of a country taking into consideration the expenditure and the investments of the two previous years and not only the immediately previous one. Later we find the saddle-point and deal with its stability giving conditions concerning the coefficient of the difference equation and which are able (sufficient) and necessary in order for the saddle-point to be stable.
\end{abstract}

\section{Introduction}

First we present Samuelson's model of the national income of a country.

We make the following assumptions:

Assumption 1: The national income $T_{k}$ at time step $\kappa$ is the composition of three elements: consumer expenditure $C_{k}$, investments $I_{k}$ and government expenditure $G_{k}$.

The total national income $T_{k}$ is the sum of these three components, that is:

$$
T_{k}=C_{k}+I_{k}+G_{k}
$$

Assumption 2: The expenditure (according to Samuelson's usual model) is equivalent to the national income $T_{k}$. This income is consumed just after the acquisition time which means that the expenditure $C_{k+1}$ of time period $\kappa+1$ is equivalent to the national income $T_{k}$ of time period $\kappa$. In this particular paper we assume that expenditure depends on the national income of the previous two years.

Assumption 3: Investments depend on the change in consumption as follows: During time period $\kappa+1$ an investor compares the consumer expenditures $C_{k+1}$ of that time period with the expenditure $C_{k}$ of the previous time period using the difference $C_{k+1}-C_{k}$.

If the consumption increases, more industries are needed for the production of consumer goods; thus, investments take place. The bigger the rise in consumer expenditure the more investments will take place. On the other hand if consumption decreases, investors block funds which had been invested; therefore, investments are reduced.

In this particular paper we considered that the investments depend on the change in consumption of the last two years.

Assumption 4: We assume that government expenditure $G_{k}$ is stable.

Using the above assumptions we are led to a difference equation which reflects Samuelson's model.

\section{Main Results}

\subsection{Finding a Difference Equation Which Reflects Samuelson's Model}

As we mentioned in the introduction, national income $T_{k}$ of time period $\kappa$ is the combination of two elements: expenditure $C_{k}$ and investments $I_{k}$. The total national income $T_{k}$ is the sum of these two elements, that is $T_{k}=C_{k}+I_{k}(1)$.

We consider that the expenditures depend on the national income of the previous two periods of time. We also assume that there is stable government spending P on both previous periods of time. The reason we expanded the Samuelson's model from one to two years is the assumption that a country's national income does not depend solely on factors of the previous year but for many year. The former assumption is expressed mathematically by the equation: 


$$
\mathrm{C}_{\mathrm{k}}=\mathrm{c}_{1} \cdot \mathrm{T}_{\mathrm{k}-1}+\mathrm{c}_{2} \cdot \mathrm{T}_{\mathrm{k}-2}+\mathrm{P}, 0<\mathrm{c}_{1}+\mathrm{c}_{2}<1 \text { and } \mathrm{c}_{1}>\mathrm{O}, \mathrm{c}_{2}>0
$$

We also consider that the investments depend on the change in consumption of both previous periods of time as following:

During the time period $\kappa$ an investor compares the expenditure $\mathrm{C} \kappa$ of that period with the expenditure $\mathrm{C}_{\mathrm{k}-1}$ of the previous period taking the difference $\mathrm{C} \kappa-\mathrm{C}_{\mathrm{k}-1}$. He also compares the expenditure $\mathrm{C}_{\mathrm{k}-1}$ with the expenditure $\mathrm{C}_{\mathrm{k}-2}$ of the time period $\mathrm{k}-2$ using the difference $\mathrm{C}_{\mathrm{k}-1}-\mathrm{C}_{\mathrm{k}-2}$.

All the above are expressed mathematically by the relationship:

$$
\mathrm{I}_{\mathrm{k}}=\mathrm{b}_{1} \cdot\left(\mathrm{C}_{\mathrm{k}}-\mathrm{C}_{\mathrm{k}-1}\right)+\mathrm{b}_{2} \cdot\left(\mathrm{C}_{\mathrm{k}-1}-\mathrm{C}_{\mathrm{k}-2}\right) \text { when } \mathrm{b}_{1}>0 \text { and } \mathrm{b}_{2}>0
$$

We continue combining the above equations (1), (2), (3) in order to create an equation which expresses Samuelson's model.

Specifically, in equation (2) we use $\kappa-1$ instead of $\kappa$. Then we have:

$$
\mathrm{C}_{\mathrm{k}-1}=\mathrm{c}_{1} \cdot \mathrm{T}_{\mathrm{k}-2}+\mathrm{c}_{2} \cdot \mathrm{T}_{\mathrm{k}-3}+\mathrm{P}
$$

Also, in equation (2) we use $\kappa-2$ instead of $\kappa$. Then we have:

$$
\mathrm{C}_{\mathrm{k}-2}=\mathrm{c}_{1} \cdot \mathrm{T}_{\mathrm{k}-3}+\mathrm{c}_{2} \cdot \mathrm{T}_{\mathrm{k}-4}+\mathrm{P}
$$

From equations (1) and (3) we have:

$$
\mathrm{T}_{\mathrm{k}}=\mathrm{C}_{\mathrm{k}}+\mathrm{b}_{1} \cdot \mathrm{C}_{\mathrm{k}}-\mathrm{b}_{1} \cdot \mathrm{C}_{\mathrm{k}-1}+\mathrm{b}_{2} \cdot \mathrm{C}_{\mathrm{k}-1}-\mathrm{b}_{2} \cdot \mathrm{C}_{\mathrm{k}-2}=\left(1+\mathrm{b}_{1}\right)^{\cdot} \mathrm{C}_{\mathrm{k}}+\left(\mathrm{b}_{2}-\mathrm{b}_{1}\right) \cdot \mathrm{C}_{\mathrm{k}-1}-\mathrm{b}_{2} \cdot \mathrm{C}_{\mathrm{k}-2} \text { when } \mathrm{b}_{1}>0 \text { and } \mathrm{b}_{2}>0
$$

We replace $C_{k}, C_{k-1}$ and $C_{k-2}$ from (2), (4), (5) and we have:

$$
\begin{gathered}
\mathrm{T}_{\mathrm{k}}=\left(\mathrm{b}_{1}+1\right) \cdot\left(\mathrm{c}_{1} \mathrm{~T}_{\mathrm{k}-1}+\mathrm{c}_{2} \mathrm{~T}_{\mathrm{k}-2}+\mathrm{P}\right)+\left(\mathrm{b}_{2}-\mathrm{b}_{1}\right) \cdot\left(\mathrm{c}_{1} \mathrm{~T}_{\mathrm{k}-2}+\mathrm{c}_{2} \mathrm{~T}_{\mathrm{k}-3}+\mathrm{P}\right)-\mathrm{b}_{2} \cdot\left(\mathrm{c}_{1} \mathrm{~T}_{\mathrm{k}-3}+\mathrm{c}_{2} \mathrm{t}_{\mathrm{k}-4}+\mathrm{P}\right)= \\
\mathrm{c}_{1} \cdot\left(\mathrm{b}_{1}+1\right) \cdot \mathrm{T}_{\mathrm{k}-1}+\left(\mathrm{c}_{2} \cdot \mathrm{b}_{1}+\mathrm{c}_{2}+\mathrm{b}_{2} \cdot \mathrm{c}_{1}-\mathrm{b}_{1} \cdot \mathrm{c}_{1}\right) \cdot \mathrm{T}_{\mathrm{k}-2}+\left(\mathrm{b}_{2} \cdot \mathrm{c}_{2}-\mathrm{b}_{1} \cdot \mathrm{c}_{2}-\mathrm{b}_{2} \cdot \mathrm{c}_{1}\right) \cdot \mathrm{T}_{\mathrm{k}-3}-\mathrm{b}_{2} \cdot \mathrm{c}_{2} \cdot \mathrm{T}_{\mathrm{k}-4}+\mathrm{P} \Leftrightarrow \\
\mathrm{T}_{\mathrm{k}}+\left(-\mathrm{c}_{1} \cdot \mathrm{b}_{1}-\mathrm{c}_{1}\right) \cdot \mathrm{T}_{\mathrm{k}-1}+\left(\mathrm{b}_{1} \cdot \mathrm{c}_{1}-\mathrm{c}_{2} \cdot \mathrm{b}_{1}-\mathrm{c}_{2}-\mathrm{b}_{2} \cdot \mathrm{c}_{1}\right) \cdot \mathrm{T}_{\mathrm{k}-2}+\left(\mathrm{b}_{2} \cdot \mathrm{c}_{1}+\mathrm{b}_{1} \cdot \mathrm{c}_{2}-\mathrm{b}_{2} \cdot \mathrm{c}_{2}\right) \cdot \mathrm{T}_{\mathrm{k}-3}+ \\
+\mathrm{b}_{2} \cdot \mathrm{c}_{2} \cdot \mathrm{T}_{\mathrm{k}-4}=\mathrm{P}
\end{gathered}
$$

We define:

$$
\begin{aligned}
& A=-c_{1} \cdot b_{1}-c_{1} \\
& B=b_{1} \cdot c_{1}-c_{2} \cdot b_{1}-c_{2}-b_{2} \cdot c_{1} \\
& C=b_{2} \cdot c_{1}+b_{1} \cdot c_{2}-b_{2} \cdot c_{2} \\
& D=b_{2} \cdot c_{2}
\end{aligned}
$$

Therefore the equation becomes:

$$
\mathrm{T}_{\mathrm{K}}+\mathrm{A} \cdot \mathrm{T}_{\mathrm{k}-1}+\mathrm{B} \cdot \mathrm{T}_{\mathrm{k}-2}+\mathrm{C} \cdot \mathrm{T}_{\mathrm{k}-3}+\mathrm{D} \cdot \mathrm{T}_{\mathrm{k}-4}=\mathrm{P}
$$

We replace $\kappa$ with $\kappa+4$. So the previous equation becomes:

$$
\mathrm{T}_{\kappa+4}+\mathrm{A}^{\cdot} \mathrm{T}_{\kappa+3}+\mathrm{B} \cdot \mathrm{T}_{\kappa+2}+\mathrm{C} \cdot \mathrm{T}_{\kappa+1}+\mathrm{D} \cdot \mathrm{T}_{\mathrm{K}}=\mathrm{P}
$$

which is a difference equation and which expresses Samuelson's model for the national income of a country.

\subsection{Specifying the Saddle-Points of Samuelson's Equation (6)}

Let's assume that we have the difference equation:

$$
g_{\kappa+n}=f\left(\kappa, g_{\kappa+n-1}, g_{\kappa+n-2}, \ldots, g_{\kappa}\right)
$$

\section{Definition 2.2.1}

A real number $\alpha$ is called saddle-point of equation (7) if assuming that $\mathrm{g}_{0}=\alpha$ it also applies that $\mathrm{g}_{\kappa+\mathrm{i}}=\alpha$ where $\kappa=1,2, \ldots$ and $\mathrm{i}=0,1, \ldots, \mathrm{n}$. This means that $\mathrm{g}_{\mathrm{k}+\mathrm{i}}=\alpha$ is a stable solution of the equations set.

According to definition 2.1.1 we put $\mathrm{T}_{\kappa}=\mathrm{T}_{\kappa+1}=\mathrm{T}_{\kappa+2}=\mathrm{T}_{\kappa+3}=\mathrm{T}_{\kappa+4}=\mathrm{S}$ in equation (6)

Then from (6) results

$$
\begin{gathered}
S+A \cdot S+B \cdot S+C \cdot S+D \cdot S=P \Leftrightarrow S \cdot(1+A+B+C+D)=P \\
1+A+B+C+D=1-c_{1} \cdot b_{1}-c_{1}+b_{1} \cdot c_{1}-c_{2} \cdot b_{1}-c_{2}-b_{2} \cdot c_{1}+b_{2} \cdot c_{1}+b_{1} \cdot c_{2}-b_{2} \cdot c_{2}++c_{2} \cdot b_{2}=1-c_{1}-c_{2}
\end{gathered}
$$

Therefore $\mathrm{S} \cdot\left(1-\mathrm{c}_{1}-\mathrm{c}_{2}\right)=\mathrm{P} \Leftrightarrow \mathrm{S}=\frac{P}{1-c_{1}-c_{2}}$ because we have assumed that $0<\mathrm{c}_{1}+\mathrm{c}_{2}<1$.

Thus the saddle-point of $(6)$ is $\mathrm{S}=\frac{P}{1-c_{1}-c_{2}}$ 


\subsection{Definition of the Conditions That Make Stable the Saddle-Point}

Equation (6) is a $4^{\text {th }}$ order non homogeneous difference equation.

The equivalent homogeneous equation of this one is:

$$
\mathrm{T}_{\kappa+4}+\mathrm{A} \cdot \mathrm{T}_{\kappa+3}+\mathrm{B} \cdot \mathrm{T}_{\kappa+2}+\mathrm{C} \cdot \mathrm{T}_{\kappa+1}+\mathrm{D} \cdot \mathrm{T}_{\mathrm{K}}=0
$$

which has a characteristic equation:

$$
\mathrm{r}^{4}+\mathrm{A} \cdot \mathrm{r}^{3}+\mathrm{B} \cdot \mathrm{r}^{2}+\mathrm{C} \cdot \mathrm{r}+\mathrm{D}=0
$$

According to the methods of solving difference equations (see "Discrete Dynamic Systems" Gr. H. Kalogeropoulos, "An Introduction to Difference Equations" S. N. Elaydi and "Introduction to Difference Equations" S. Coldberg)

the saddle-point

$\mathrm{S}=\frac{P}{1-c_{1}-c_{2}}$ will be asymptotically stable if $\left|r_{i}\right|<1 \mathrm{i}=1,2,3,4$, where $\mathrm{r}_{1}, \mathrm{r}_{2}, \mathrm{r}_{3}, \mathrm{r}_{4}$ are the roots of equation (9) not necessarily discrete

From the above results we have the deduction:

For a saddle-point to be asymptotically stable all the roots of the characteristic equation must have magnitude less than one.

\section{Definition 2.3.1}

Let $\mathrm{V}$ be a vector space over a field $\mathrm{F}(=\mathrm{R}$ or $\mathrm{C})$.

A function \|\|$: \mathrm{V} \rightarrow \mathrm{R}^{+}: \vec{x} \rightarrow\|\vec{x}\|$ is called a norm if it satisfies the following conditions:

1) $\|\vec{x}\| \geq 0$ for all $\vec{x} \in V, \vec{x} \neq \vec{o}$ and $\|\overrightarrow{0}\|=0$

2) For all $a \in F, \vec{x} \in V \quad$ we have $\|a \cdot \vec{x}\|=|a| \cdot\|\vec{x}\|$

3) For all $\vec{x}, \vec{y} \in V \quad$ we have $\|\vec{x}+\vec{y}\| \leq\|\vec{x}\|+\|\vec{y}\|$

There are a lot of vector norms but we will use here the maximum norm or infinity norm $\left(\ell_{\infty}\right.$-norm) on $\mathrm{R}^{\mathrm{n}}$ (or $\mathrm{C}^{\mathrm{n}}$ ).

We consider a function \|\|$_{\infty}: \mathrm{R}^{n} \rightarrow R^{+}$

For all $\vec{x}=\left[x_{1}, x_{2}, \ldots \ldots \ldots \mathrm{x}_{n}\right]^{t} \in R^{n} \rightarrow\|\vec{x}\|_{\infty}:=\max \quad\left\{\left|x_{1}\right|,\left|x_{2}\right| \ldots . .\left|x_{n}\right|\right\}$

We now consider a set of $\mathrm{n} \times \mathrm{n}$ matrices which, expressed as $\mathrm{Mn}, n \in N \quad$ with elements from $\mathrm{C}$ or $\mathrm{R}$. ( $N$ is the set of not negative integer)

That is if $\mathrm{A} \in \mathrm{Mn}$, then $\mathrm{A}$ is a $\mathrm{n} \mathrm{x}$ matrix and $\mathrm{Mn}=\mathrm{R}^{\mathrm{nxn}}$ ( or $\mathrm{C}^{\mathrm{nxn}}$ )

\section{Definition 2.3.2}

A function \|\|$\|: \mathrm{R}^{\mathrm{nxn}}\left(\right.$ or $\left.\mathrm{C}^{\mathrm{nxn}}\right) \rightarrow \mathrm{R}^{+}$is a matrix norm

if for all $\mathrm{A}, \mathrm{B} \in \mathrm{R}^{\mathrm{nxn}}\left(\right.$ or $\left.\mathrm{C}^{\mathrm{nxn}}\right)$ satisfies the following four conditions:

1) $\|A\| \| \geq 0$ and $\|A\| \|=0$ if and only if $\mathrm{A}=0$

2) $\|c A\||=| c|\|A\|| \quad c \in \mathrm{R}$ (or $\mathrm{c} \in \mathrm{C}$ )

3) $\|A+B\| \leq\|A\|+\|B\|$ (triangle inequality)

4) $\|A \cdot B\| \mid \leq\|A\| \cdot\|\cdot\| B \|$ (submultiplicative)

In this particular paper we will use \|\|$_{\infty}$ row sum norm which has the following form: $\|A\| \|_{\infty}=\max _{1 \leq i \leq n} \sum_{j=1}^{n}\left|a_{i, j}\right|$

Now we will prove the next statement which we will need for the proof of the theorem 2.3.1. 


\section{Lemma 2.3.1}

Let $\mathrm{A} \in \mathrm{R}^{\mathrm{nxn}}\left(\right.$ or $\mathrm{C}^{\mathrm{nxn}}$ ) be a $\mathrm{n} \mathrm{x}$ n matrix and $\vec{x} \in \mathrm{R}^{\mathrm{n}}\left(\right.$ or $\left.\mathrm{C}^{\mathrm{n}}\right), \vec{x}=\left[x_{1}, x_{2}, \ldots \ldots . . x_{n}\right]^{t}$ $\mathrm{A}=\left[a_{i, j}\right]_{i, j=1,2, \ldots . . n} \quad a_{i, j} \in R$ (or $\mathrm{C}$ ) then $\|A \cdot \vec{x}\|_{\infty} \leq\|A\|_{\infty} \cdot\|\vec{x}\|_{\infty}$ is true.

(Notice that $\|A \cdot \vec{x}\|_{\infty}$ is a vector norm while $\|A\| \|_{\infty}$ is a matrix norm.)

Proof

$$
\|A \cdot \vec{x}\|_{\infty}=\max _{i=1,2, \ldots, n}\left|\sum_{j=1}^{n} a_{i, j} \cdot x_{j}\right| \leq \max _{i=1,2, \ldots n} \sum_{j=1}^{n}\left|a_{i, j} \cdot x_{j}\right| \leq \max _{i=1,2, \ldots n} \sum_{j=1}^{n}\left|a_{i, j}\right| \cdot\|\vec{x}\|_{\infty}=\|A\|\left\|_{\infty} \cdot\right\| \vec{x} \|_{\infty} .
$$

We are going now to theorem 3.2.1 which will play an important role.

Theorem 2.3.1

Let $\mathrm{P}(\mathrm{x})=\alpha_{\mathrm{n}} \mathrm{x}^{\mathrm{n}}+\ldots \ldots \ldots+\alpha_{1} \mathrm{x}+\alpha_{0}$ be a polynomial, $\alpha_{\mathrm{i}} \in \mathrm{C} \forall \mathrm{i}=1,2, \ldots . \mathrm{n} \mathrm{a}_{\mathrm{n}} \neq 0 \mathrm{n} \in \mathrm{N}$

The $\mathrm{n}$ roots of the polynomial are in a circular disk of center $(0,0)$ and radius

$\mathrm{p}=\max \left\{1, \sum_{i=0}^{n-1}\left|\frac{a_{i}}{a_{n}}\right|\right\}(||=$ absolute value of a complex number $)$

\section{Proof}

Let $\mathrm{x}_{1}, \mathrm{x}_{2}, \ldots, \mathrm{x}_{\mathrm{n}}$ be the roots of the polynomial $\mathrm{P}(\mathrm{x})$ not necessarily different among them. Let $\mathrm{x}$ be one solution of:

$$
\begin{aligned}
& \mathrm{P}(\mathrm{x})=0 \Leftrightarrow \alpha_{\mathrm{n}} \mathrm{x}^{\mathrm{n}}+\ldots \ldots \ldots+\alpha_{1} \mathrm{x}+\alpha_{0}=0 \Leftrightarrow \alpha_{\mathrm{n}} \mathrm{x}^{\mathrm{n}}=-a_{0}-a_{1} \cdot x-\ldots \ldots-a_{n-1} \cdot x^{n-1} \Leftrightarrow \\
& x^{n}=-\frac{a_{0}}{a_{n}}-\frac{a_{1}}{a_{n}} \cdot x-\ldots \ldots \ldots-\frac{a_{n-1}}{a_{n}} \cdot x^{n-1} \\
& \text { Let } \mathrm{A}=\left[\begin{array}{ccccc}
0 & 1 & 0 & \ldots & 0 \\
0 & 0 & 1 & \ldots & 0 \\
\ldots & \ldots & \ldots & \ldots & \ldots \\
0 & \ldots & & 0 & 1 \\
-\frac{a_{0}}{a_{n}} & -\frac{a_{1}}{a_{n}} & \ldots & \ldots & -\frac{a_{n-1}}{a_{n}}
\end{array}\right] \text { be a n x n matrix } \\
& \text { and vector } \vec{u}=\left[\begin{array}{c}
1 \\
x \\
x^{2} \\
\vdots \\
x^{n-1}
\end{array}\right] \quad, \vec{u} \neq \overrightarrow{0}
\end{aligned}
$$




$$
\begin{aligned}
& \mathrm{A} \vec{u}=\left[\begin{array}{ccccc}
0 & 1 & 0 & \ldots & 0 \\
0 & 0 & 1 & \ldots & 0 \\
\ldots & \ldots & \ldots & \ldots & \ldots \\
0 & \ldots & & 0 & 1 \\
-\frac{a_{0}}{a_{n}} & -\frac{a_{1}}{a_{n}} & \ldots & \ldots & -\frac{a_{n-1}}{a_{n}}
\end{array}\right]\left[\begin{array}{c}
1 \\
x \\
x^{2} \\
\vdots \\
x^{n-1}
\end{array}\right]= \\
& =\left[\begin{array}{c}
x \\
x^{2} \\
\vdots \\
x^{n-1} \\
-\frac{a_{0}}{a_{n}}-\frac{a_{1}}{a_{n}} x-\cdots-\frac{a_{n-1}}{a_{n}} x^{n-1}
\end{array}\right]=\left[\begin{array}{c}
x \\
x^{2} \\
\vdots \\
x^{n-1} \\
x^{n}
\end{array}\right]=x \cdot\left[\begin{array}{c}
1 \\
x \\
\vdots \\
x^{n-2} \\
x^{n-1}
\end{array}\right]=x \cdot \vec{u}
\end{aligned}
$$

Therefore we have $A \cdot \vec{u}=x \cdot \vec{u}$

We use the infinity norm \|\|$_{\infty}$ for vectors. Then from

$$
A \cdot \vec{u}=x \cdot \vec{u} \Rightarrow\|A \cdot \vec{u}\|_{\infty}=\|x \cdot \vec{u}\|_{\infty}=|x| \cdot\|\vec{u}\|_{\infty} .
$$

From the statement(2.3.1) we have $\|A \cdot \vec{u}\|_{\infty} \leq\|A\|_{\infty} \cdot\|\vec{u}\| \|_{\infty}$

Therefore $|x| \cdot\|\vec{u}\|_{\infty} \leq\|A\|_{\infty} \cdot\|\vec{u}\|_{\infty}, \vec{u} \neq \overrightarrow{0}$ thus $\|\vec{u}\|_{\infty}>0$ thus $|x| \leq\|A\|_{\infty}$

We have $\|A\|_{\infty}=\max \left\{1, \sum_{i=0}^{n-1}\left|\frac{a_{i}}{a_{n}}\right|\right\} \quad$ because all rows of matrix A contain only the value 1, except for the last one row where the sum of its elements is $\sum_{i=0}^{n-1}\left|-\frac{a_{i}}{a_{n}}\right|=\sum_{i=0}^{n-1}\left|\frac{a_{i}}{a_{n}}\right|$

So the solution of equation $\mathrm{P}(\mathrm{x})=0$ is in the interior and in the disk of center $(0,0)$ and radius $\mathrm{P}=\|\mid\| A\|\|_{\infty}$

That is $\mathrm{x} \in \bar{S}\left(0,\|A\|_{\infty}\right)=\left\{\mathrm{y} \in \mathrm{C}:|y| \leq\|A \mid\|_{\infty}\right\}$

We now return to the check of the stability of the saddle-point.

We have the polynomial (9):

$$
\mathrm{r}^{4}+\mathrm{Ar}^{3}+\mathrm{Br}^{2}+\mathrm{Cr}+\mathrm{D}=0
$$

According to theorem 2.3.1 the roots of the polynomial will be in disk of center $(0,0)$ and radius $\mathrm{p}=\max \{1,|\mathrm{~A}|+|\mathrm{B}|+|\mathrm{C}|$ $+|\mathrm{D}|\}$.

\section{Lemma 2.3.2}

If $|\mathrm{A}|+|\mathrm{B}|+|\mathrm{C}|+|\mathrm{D}|<1$, then the roots of the polynomial equation $\mathrm{r}^{4}+\mathrm{Ar}^{3}+\mathrm{Br}^{2}+\mathrm{Cr}+\mathrm{D}=0$ have absolute value less than one.

\section{Proof}

If $|\mathrm{A}|+|\mathrm{B}|+|\mathrm{C}|+|\mathrm{D}|<1$, then $\mathrm{p}=\max \{1,|\mathrm{~A}|+|\mathrm{B}|+|\mathrm{C}|+|\mathrm{D}|\}=1$.

Therefore, according to theorem 2.3.1, if $r$ is the root of (9), then $|r| \leq 1$.

We will prove that $|r| \neq 1$.

Let $\mathrm{f}(\mathrm{r})=\mathrm{r}^{4}+\mathrm{Ar}^{3}+\mathrm{Br}^{2}+\mathrm{Cr}+\mathrm{D}$ and let there be $\mathrm{z} \in \mathrm{C}$ with $|\mathrm{z}|=1$ and $\mathrm{f}(\mathrm{z})=0$.

The $\mathrm{F}(\mathrm{r})$ is a $4^{\text {th }}$ degree polynomial with real coefficients $\mathrm{A}, \mathrm{B}, \mathrm{C}, \mathrm{D}$ and $|\mathrm{A}|<1$, 
$|\mathrm{B}|<1,|\mathrm{C}|<1,|\mathrm{D}|<1$, because we assumed that $|\mathrm{A}|+|\mathrm{B}|+|\mathrm{C}|+|\mathrm{D}|<1$.

(| | is the absolute value of a real number).

We notice that $\mathrm{z}=1$ is not a solution of $\mathrm{f}(\mathrm{r})=0$ because if

$$
\begin{aligned}
& \mathrm{f}(1)=0 \Leftrightarrow 1+A+B+C+D=1-c_{1} \cdot b_{1}-c_{1}+b_{1} \cdot c_{1}-c_{2} \cdot b_{1}-c_{2}-b_{2} \cdot c_{1}+b_{2} \cdot c_{1}+b_{1} \cdot c_{2}-b_{2} \cdot c_{2}+b_{2} \cdot c_{2}= \\
& =1-\mathrm{c}_{1}-\mathrm{c}_{2}>0
\end{aligned}
$$

as it arises from equation (2).

Therefore, concerning the roots of polynomial $\mathrm{f}(\mathrm{r})$, if $|\mathrm{r}|=1$ our options are:

a)It has the solution $\mathrm{z}=-1$ with multiplicity of 4 .

b)It has the solution $\mathrm{z}=-1$ with multiplicity of 2 and two complex conjugate roots (let them be $z_{0}, \overline{z_{0}}$ having $\left|z_{0}\right|=1$ $=\left|z_{0}\right|$ ).

c)It has two complex conjugate roots, each one with multiplicity of 2 (let them be $z_{0}, \overline{z_{0}}$, having ||$z_{0}|=1=| \overline{z_{0}} \mid$ ).

d)It has 4 complex roots $z_{1}, \overline{z_{1}}, z_{2}, \overline{z_{2}} \mathrm{z}$ in conjugate pairs, having

$$
\left|z_{1}\right|=\left|\overline{z_{1}}\right|=\left|z_{2}\right|=\left|\overline{z_{2}}\right|=1
$$

If we have option (a), then

$$
\mathrm{f}(\mathrm{z})=(\mathrm{z}+1)^{4} \Leftrightarrow z^{4}+A \cdot z^{3}+B \cdot z^{2}+C \cdot z+D=z^{4}+4 \cdot z^{3}+6 \cdot z^{2}+4 \cdot z+1 \quad \forall z \in C .
$$

Thus, $\mathrm{A}=4, \mathrm{~B}=6, \mathrm{C}=4$ and $\mathrm{D}=1$ which is a contradiction because

$$
|\mathrm{A}|,|\mathrm{B}|,|\mathrm{C}|,|\mathrm{D}|<1 \text {. }
$$

If we have option (b), then:

$$
\begin{gathered}
\mathrm{f}(\mathrm{z})=(z+1)^{2} \cdot\left(z-z_{0}\right) \cdot\left(z-\overline{z_{0}}\right) \Leftrightarrow \\
z^{4}+A \cdot z^{3}+B \cdot z^{2}+C \cdot z+D=\left(z^{2}+2 \cdot z+1\right) \cdot\left[z^{2}-\left(z_{0}+\overline{z_{0}}\right) \cdot \mathrm{z}+\mathrm{z}_{0} \cdot \overline{z_{0}}\right]
\end{gathered}
$$

Then $z_{0} \cdot \overline{z_{o}}=\left|z_{0}\right|^{2}=1$ from the properties of conjugate complex numbers. Therefore we have:

$$
z^{4}+A \cdot z^{3}+B \cdot z^{2}+C \cdot z+D=z^{4}+\left(2-z_{0}-\overline{z_{0}}\right) \cdot z^{3}+\left(2-2 \cdot z_{0}-2 \cdot \overline{z_{0}}\right) \cdot z^{2}+\left(2-z_{0}-\overline{z_{0}}\right) \cdot \mathrm{z}+1 \quad \forall z \in C
$$

Thus, $\mathrm{D}=1$ which is a contradiction because $|\mathrm{D}|<1$.

If we have option (c), then

$$
\begin{aligned}
& f(z)=\left(z-z_{0}\right)^{2} \cdot\left(z-\overline{z_{0}}\right)^{2} \Leftrightarrow z^{4}+A \cdot z^{3}+B \cdot z^{2}+C \cdot z+D=\left[z^{2}-\left(z_{0}+\overline{z_{0}}\right) \cdot z+z_{0} \cdot \overline{z_{0}}\right]^{2} \stackrel{\alpha_{0}^{*}<0-<0 \mid-1}{\Leftrightarrow} \\
& z^{4}+A \cdot z^{3}+B \cdot z^{2}+C \cdot z+D=z^{4}+\left(z_{0}+\overline{z_{0}}\right)^{2} \cdot z^{2}+1-2 \cdot\left(z_{0}+\overline{z_{0}}\right) \cdot z^{3}-2 \cdot\left(z_{0}+\overline{z_{0}}\right) \cdot \mathrm{z}+2 \cdot z^{2} \Leftrightarrow \\
& z^{4}+A \cdot z^{3}+B \cdot z^{2}+C \cdot z+D=z^{4}-2 \cdot\left(z_{0}+\overline{z_{0}}\right) \cdot z^{3}+\left[2+\left(z_{0}+\overline{z_{0}}\right)^{2}\right] \cdot z^{2}-2 \cdot\left(z_{0}+\overline{z_{0}}\right) \cdot z+1, \forall z \in C
\end{aligned}
$$

This means that $\mathrm{D}=1$, which is a contradiction because $|\mathrm{D}|<1$.

If we have option (d), then

$$
\begin{aligned}
f(z) & =\left(z-z_{1}\right) \cdot\left(\mathrm{z}-\overline{z_{1}}\right) \cdot\left(z-z_{2}\right) \cdot\left(z-\overline{z_{2}}\right) \Leftrightarrow z^{4}+A \cdot z^{3}+B \cdot z^{2}+C \cdot z+D \\
= & {\left[z^{2}-\left(z_{1}+\overline{z_{1}}\right) \cdot z+z_{1} \cdot \overline{z_{1}}\right] \cdot\left[z^{2}-\left(z_{2}+\overline{z_{2}}\right) \cdot z+z_{2} \cdot \overline{z_{2}}\right] \Leftrightarrow } \\
& z^{4}+A \cdot z^{3}+B \cdot z^{2}+C \cdot z+D=\left[z^{2}-\left(z_{1}+\overline{z_{1}}\right) \cdot z+1\right] \cdot\left[z^{2}-\left(z_{2}+\overline{z_{2}}\right) \cdot z+1\right]
\end{aligned}
$$




$$
\text { Because } z_{1} \cdot \overline{z_{1}}=\left|z_{1}\right|^{2}=z_{2} \cdot \overline{z_{2}}=\left|z_{2}\right|^{2}=1
$$

We have

$$
\begin{gathered}
z^{4}+A \cdot z^{3}+B \cdot z^{2}+C \cdot z+D= \\
z^{4}-\left(z_{1}+\overline{z_{1}}+z_{2}+\overline{z_{2}}\right) \cdot z^{3}+\left[2+\left(z_{1}+\overline{z_{1}}\right) \cdot\left(z_{2}+\overline{z_{2}}\right)\right] \cdot \mathrm{z}^{2}-\left(z_{1}+\overline{z_{1}}+z_{2}+\overline{z_{2}}\right) \cdot \mathrm{z}+1, \forall \mathrm{z} \in \mathrm{C}
\end{gathered}
$$

So it has to be $\mathrm{D}=1$, which is a contradiction because $|\mathrm{D}|<1$.

In conclusion, if $r$ is the solution of $f(z)=0$, then $|r| \leq 1$ and since we have shown that $|r| \neq 1$, then $|r|<1$. This means that all the roots of the characteristic equation (9) have absolute value less than one.

So far we have seen that the saddle-point given by the equation which expresses Samuelson's model of national economy is asymptotically stable when:

$|\mathrm{A}|+|\mathrm{B}|+|\mathrm{C}|+|\mathrm{D}|<1$

where: $\quad A=-c_{1} \cdot b_{1}-c_{1}$

$$
\begin{aligned}
& \mathrm{B}=\mathrm{b}_{1} \cdot \mathrm{c}_{1}-\mathrm{c}_{2} \cdot \mathrm{b}_{1}-\mathrm{c}_{2}-\mathrm{b}_{2} \cdot \mathrm{c}_{1} \\
& \mathrm{C}=\mathrm{b}_{2} \cdot \mathrm{c}_{1}+\mathrm{b}_{1} \cdot \mathrm{c}_{2}-\mathrm{b}_{2} \cdot \mathrm{c}_{2} \\
& \mathrm{D}=\mathrm{b}_{2} \cdot \mathrm{c}_{2}
\end{aligned}
$$

$$
0<c_{1}+c_{2}<1, c_{1}>0, c_{2}>0, b_{1}>0, b_{2}>0
$$

More specifically, condition (11) becomes:

$$
\begin{gathered}
\left|-c_{1} \cdot b_{1}-c_{1}\right|+\left|b_{1} \cdot c_{1}-c_{2} \cdot b_{1}-c_{2}-b_{2} \cdot c_{1}\right|+\left|b_{2} \cdot c_{1}+b_{1} \cdot c_{2}-b_{2} \cdot c_{2}\right|+\left|b_{2} \cdot c_{2}\right|<1 \Leftrightarrow \\
c_{1} \cdot b_{1}+c_{1}+\left|b_{1} \cdot c_{1}-c_{2} \cdot b_{1}-c_{2}-b_{2} \cdot c_{1}\right|+\left|b_{2} \cdot c_{1}+b_{1} \cdot c_{2}-b_{2} \cdot c_{2}\right|+b_{2} \cdot c_{2}<1
\end{gathered}
$$

\section{Conclusions}

In this paper we studied Samuelson's model of national economy taking into account the investments and expenditure of the previous two years. We discovered the saddle-point and gave the condition to be asymptotically stable.

As a future paper we will generalize Samuelson's model for more than two past years and we will look for conditions that make asymptotically stable saddle-point.

We will also study conditions (11) geometrically in the plane so that we can find sectors consisting of points which if we replace its ordinates in Samuelson's equation, the saddle-point will be asymptotically stable.

\section{References}

Apostolopoulos, N., Ortega, F., \& Kalogeropoulos, G. (2016). The Samuelson model as a similar discrete time system. Arxiv preprint at Xiv :1705.01350

Apostolopoulos, N., Ortega, F., \& Kalogeropoulos, G. (2015). Causality of singular linear discrete time systems. arXiv preprint arXiv:1512.04740

Afici, F. M., \& Eloe, P. W. (2011). Linear system of fractional nabla difference equations. The Rocky Mountain Journal of Mathematics, 41(2), pr353370.

Chari, V. V. (1994). Optimal Fiscar Policy in a Business Cycle Model. Journal of Political Economy, $102(4), 52-61$.

Chow, G. C. (1985). A model or Chinese National Income Determination. Journal of Political Economy, 93(4), $782-792$.

Elaydi, S. N. (1999). An Introduction to Difference Equations Springer.

Goldberg, S. (1986). Introduction to difference Equations Dover.

Levy, H., \& Lessman, F. (1961). Finite Difference Equations Dover.

Leonard, I. E. (1996). The matrix exponential SIAM Review, 38(3), 507-512.

Mickens, R. (1987) Difference Equations, Theory and Applications Van Nostrand Reinhold. 
Ogata, K. (1987). Discrete time control systems Prentice Hall

Fernado, O., Maria, P. B., \& Grigoris, K. (2017). equilibrium for a reformulated Samuelson economical model arXiv 170608298

Ruu, T., Cardini, L., \& Sushko, I. (2004). A Hicksian multiplier accelerator model with floor determined by capital stock. Journal of Economic Behavior and organization, 56.

Qian, C. (2010). The Balassa-samuelson model of purchasing power parity and Chinese exchange rates. China Economics review, 21, 334-345.

Ruth, W. J. (1996). Linear system theory . Prentice hall International UK London.

Samuelson, P. (1939). Interactions between the multiplier analysis and the principle of acceleration Review of Economic Statistics.

Soo, K. T. (2018). The gains from trade in international goods .A Ricardo -Sraffa-Samuelson model in international Review of Economics and finance, 54, 244-261.

L Verde-Star operator identities and the solution of linear matrix difference and differential equations. Studies in Applied mathematics, 91(1994), 153-177

Westerhoff, F. H. (2006). Samuelson's multiplier-accelerator model revisited. Applied Economics letters, 56, 86-92.

Wicoop, E. A. (1996). A multi-country real business cycle model Scand. Journal of economics, 23, $233-251$.

\section{Copyrights}

Copyright for this article is retained by the author(s), with first publication rights granted to the journal.

This is an open-access article distributed under the terms and conditions of the Creative Commons Attribution license (http://creativecommons.org/licenses/by/4.0/). 